\title{
Peran Madarasah Diniyah Dalam Mengembangkan Pendidikan Untuk Menghadapi Era Revolusi Indrustri 4.0
}

\author{
Sukma Ayu Kurvaliany \\ Dosen Fakultas Tarbiyah dan Ilmu Keguruan IAIN Ponorogo \\ Ayu50608.gmail.com \\ Yanuar Fajar Romadhon \\ Dosen Fakultas Tarbiyah dan Ilmu Keguruan IAIN Ponorogo \\ yanuarfajar9912@gmail.com

\section{Zahrotus Sya'adah} \\ Dosen Fakultas Tarbiyah dan Ilmu Keguruan IAIN Ponorogo \\ Zahrotus220@gmail.com

\section{Zulfa Ihza Melina} \\ Dosen Fakultas Tarbiyah dan Ilmu Keguruan IAIN Ponorogo \\ Zulfaihzaaa@gmail.com
}

\begin{abstract}
Madrasah diniyah and pondok pesantren are educational institutions that are very popular in Indonesia. Todays, the role of madrasah diniyah in supporting Islamic learning needs serious attention. The development of Islamic education institutions left behind with the development of science and technology in the era of the industrial revolution 4.0. The existence of Madrasah Diniyah was fade and left behind in various aspect. This paper aims to know
\end{abstract}


the problems of madrasah diniyah in the era of the industrial revolution 4.0. The method we use is literature review. This study recommends that madrasah diniyah should play a central role in the globalization era, especially in industrial revolution 4.0 era. In addition, pesantren do not only focus on studying religion and reciting the Koran, but also instill the values of nationalism as well as moral and manners, and instill skills education so that madrasah diniya can interact with the development of science and technology.

Keywords: Madrasah Diniyah, Industrial Revolution 4.0, Islamic Education.

Abstrak: Madrasah diniyah dan pondok pesantren adalah lembaga pendidikan yang sangat populer dimasyarakat. Dewasa ini, peran madrasah diniyah dalam menunjang pembelajaran Islam butuh perhatian yang serius. Perkembangan lembaga pendidikan Islam sangat terbelakang jika dibandingkan dengan perkembangan Ilmu pengetahuan dan teknologi di era revolusi industri 4.0. Eksistensi dari madrasah diniyah mulai meredup dan tertinggal dalam berbagai bidang. Tulisan ini bertujuan untuk mengangkat problematika madrasah diniyah dalam perkembangan keilmuan pada era revolusi industri 4.0. Metode yang kami gunakan adalah kajian literatur. Penelitian ini merekomendasikan bahwa seharusnya madrasah diniyah berperan sentral dalam membentengi arus globalisasi di era revolusi industri 4.0. Di samping itu, pesantren tidak hanya focus belajar agama dan mengaji saja, namun harus menanamkan nilai-nilai nasionalisme dan juga nilai moral dan adab, serta menanamkan pendidikan keterampilan agar madrasah diniyah dapat berinteraksi dengan zaman.

Kata Kunci: Madrasah Diniyah, Revolusi Industri 4.0, Pendidikan Islam.

\section{Pendahuluan}

Pada era sekarang teknologi yang sangat maju pesat sangat mempengaruhi dalam berbagai bidang, salah satunya adalah bidang pendidikan dan khususnya adalah pendidikan Islam. Pada hakikatnya pendidikan 
Islam dan teknologi perkembangan sains tidak bisa dipisahkan, sehingga pendidikan Islam pada zaman revolusi industri 4.0 ini perlu disinkronkan atau diselaraskan, salah satu lembaga pendidikan yang asli Indonesia dan sangat berperan dalam masyarakat adalah madrasah diniyah, namun dalam perkembangannya diera revolusi industri 4.0 ini madrasah diniyah semakin terpuruk dan eksistensinya semakin pudar.

Madrasah diniyah ini sangat diperlukan dalam masyarakat dan sekolah formal yang berbasis umum sehingga dapat menunjang pembelajaran pendidikan keIslaman, pendidikan keIslaman ini yang dianggap kurang berperan dalam masyarakat dan diinstansi pendidikan umum, sehingga penanaman keIslaman dan nasionalisme dapat ditanamkan melalui adanya madrasah diniyah. Madrasah diniyah adalah salaah satou pendidikan Islam yang banyak diminati di masyarakat dan khususnya dipondok pesantren ${ }^{1}$. Dalam perjalanan perkembangannya banyak sekali lika-liku yang di hadapi seiring berjalannya waktu, pada dasarnya sangat dibutuhkan sekali dalam pengembangan pendidikan Islam khususnya di masyrakat sehingga dapat menunjang pembelajaran tentang keIslaman yang kurang diperhatikan di instansi pendidikan formal khususnya yang berbasis umum.

Dengan adanya beberapa problem yang ada seperti tergerusnya eksistensi madrasah diniyah yang semakin redup, peminatnya yang sangat minim dan juga guru atau pendidik yang kurang berkompeten, itulah yang menjadi suatu kegelisahan akademik yang memotivasi kami sebagai penulis untuk mengangkat problematika tentang madrasah diniyah, dan kami merumuskan kegelisahan kami tentang bagaimana eksistensi madrasah diniyah dapat lebih eksis diera revolusi industri 4.0, bagaimana peran madrasah diniyah dalam pengembangan pendidikan diera revolusi industri 4.0, dan bagaimana dampak yang ditimbulkan oleh modernisasi diera revolusi industri 4.0.

Dari beberapa problematika dan juga kegelisahan akademik yang dirasakan oleh kami sebagai penulis merasa miris dengan adanya problematika tersebut dan akhirnya kami membuat artikel ini untuk memenuhi

1 Marwan Salahuddin, "Reposisi Dan Eksistensi Madrasah Salafiyah Di Era Global", Cendekia, Vol. 11 No. 2, (Desember 2013), 224. 
tugas mata kuliah Kapita Selekta Pendidikan Islam dan ingin membuktikan bahwa madrasah diniyah itu dapat memberikan pendidikan Islami yang sangat baik dan berkompeten, dan diartikel ini kami membuat rumusan masalah sebagai berikut yaitu apa yang dimaksud madarasah diniyah dan juga tujuan adanya madrasah diniyah, yang kedua adalah bagaimana peran madrasah diniyah diera modern revolusi indutri 4.0, yang ketiga adalah bagaimana pengembangan pendidikan Islam berbasis madrasah diniyah diera revolusi industri 4.0, dan yang terakhir adalah bagaimana dampak yang ditimbulkan dari era revolusi industri 4.0 bagi madrasah diniyah. Dari rumusan diatas kami berharap bisa memberikan kontribusi pemikiran untuk memunculkan solusi yang dapat dijadikan pedoman dalam pelaksanaan pendidikan Islam khususnya dalam madrasah diniyah.

\section{Pembahasan}

\section{A. Pengertian Madrasah Diniyah dan Tujuan Madrasah Diniyah}

Madrasah diniyah adalah lembaga pendidikan Islam khas indonesia yang berfungsi mengembangkan pemahaman religius keIslaman dan spiritulis peserta didiknya, kata madrasah sendiri sering diartikan sebagai sekolah agama Islam atau lembaga pendidikan yang mengajarkan tentang agama Islam dan apa saja yang ada didalamnya. ${ }^{2}$ Jadi dari pengertian tersebut dapat disimpulkan bahwa madrasah diniyah adalah lembaga pendidikan Islam baik non formal ataupun formal yang mengajarkan tentang agama Islam dan sebagai salah satu jawaban dari kurangnya pendidikan agama Islam dalam sekolah formal yang kurang begitu spesifik dalam mengajarkan apa itu pendidikan agama Islam dan apa saja yang ada didalamnya dan menunjang dalam pembentukan karakter, kereligiusan, spiritualitas serta yang berlandasakan sumber hukum Islam dan kitabkitab klasik sebagai rujukan belajar.

Tujuan dari adanya madrasah diniyah secara umum adalah membentuk insan yang berilmu, berkeperibadian atau berkaraker, beriman,

2 M. Jamhuri, "Upaya Pendidikan Madrasah Diniyah Dalam Meningkatkan Prestasi Belajar Siswa Pada Materi Fiqih Di Madrasah Diniyah MIftahul Ulum Pruten Ngembal Pasuruan", Al-Murabbi: Jurnal Pendidikan Islam, Vol. 2 No. 2, (Juni 2017), 318. 
bertaqwa dan beraklhakul karimah. Dan dapat dikembangkan dalam beberapa tujuan sebagai berikut, yakni:

1. Sebagai media pengajaran nilai-nilai keIslaman.

2. Pemelihara tradisi keagamaan dalam lingkup generasi muslim atau masyarakat muslim.

3. Sebagai sarana pembentukan generasi muslim yang akhlakul karimah dan berkarakter religius serta memiliki spiritualis tinggi.

4. Sebagai sara internalisasi nilai nasionalisme pada peserta didik yang berdasarkan Pancasila dan UUD 1945.

5. Sebagai lembaga pendidikan Islam yang alternatif untuk menunjang pembelajaran dan pengajaran pendidikan keIslaman dalam masyarakat. $^{3}$

Pada hakikatnya, tujuan dari adanya madrasah diniyah adalah sebagai lembaga pendidikan Islam yang membentuk dan mencetak generasi muda Islam yang memiliki karakter religius dan spiritualis serta berakhlak dan berilmu, selain itu madrasah diniyah adalah salah satu bentuk adanya upaya pendidikan yang berbasis madrasah, yang dapat dikembangkan dalam bentuk pembelajaran dan juga penanaman nilai-nilai nasionalisme peserta didik, sehingga dapat menjadi generasi muda yang tahan akan benturan modernisasi zaman seperti sekarang ini.

\section{B. Peran Madrasah Diniyah Dalam Era Revolusi Industri 4.0}

Madrasah diniyah dalam perkembangannya juga ikut andil dalam membentengi pemodernan zaman, dan beberapa peran yang sentral dari madrasah diniyah dalam era revolusi industri 4.0 adalah diantaranya madrasah diniyah adalah sarana pembekalan, pengajaran serta penanaman nilai-nilai keIslaman yang berkompeten dalam bidangnya sehingga peserta didik dapat menjadi insan yang dapat bermanfaat dunia dan akhirat, selain itu ikut andil dalam kancah pendidikan nasional sebagai penggerak dibidang pendidikan yang berstandar nasional atau menyeluruh dalam negeri dan diakui sebagai lembaga pendidikan,

\footnotetext{
3 Mohammad Toriqul Chaer, "Peran Madrasah Dalam Menghadapi Era Globalisasi Dan Budaya”, Muaddib, Vol. 6 No. 2, (Juli-Desember 2016), 194.
} 
yang ketiga adalah mampu menjawab problematika dalam kehidupan bermasyarakat sebagai pengamalan keilmuan yang dimiliki, yang keempat penanaman moral keIslaman dan nasionalisme agar terhindar dari krisis identitas dalam negeri dan menjunjung tinggi etika dan adab sebagai dasar sosial, yang kelima menciptakan sebuah iklim masyarakat yang rukun, aman, sejahtera, plural dan bertoleransi dalam kehidupan. ${ }^{4}$

Dalam pembukaan UUD 1945 dijelaskan bahwa tujuan nasional dari bansa Indonesia adalah mencerdaskan kehidupan bangsa, dalam penerapannya madrasah diniyah berperan aktif dan ikut serta dalam mencerdaskan kehidupan bangsa sebagai lembaga pendidikan yang berbasis Islam, sehingga peran yang diberikan oleh madrasah diniyah dalam masyarakat adalah mengajarkan nilai-nilai keIslaman, menjunjung tinggi moral dan adab atau etika, dan membentuk insan yang dapat bermanfaat dunia dan akhirat.

Pada era revolusi industri ini sangat disayangkan bahwa eksistensi madrasah diniyah kurang diperhatikan oleh pihak terkait dan juga masyakat kurang meminati dari pendidikan berbasis madrasah diniyah, inilah beberapa faktor yang menghambat laju peran serta madrasah diniyah dalam era modrn ini, sehingga peran yang seharusnya sentral menjadi kurang terpelihara dan mulai redup termakan perubahan zaman yang begitu pesat dan ekstrim ini.

\section{Pengembangan Pendidikan Islam Berbasis Madrasah Diniyah Dalam Era Revolusi Industri 4.0}

Pengembangan Pendidikan Islam melalui Madrasah diniyah adalah salah satu terwujudnya tujuan pendidikan, sehingga perlunya pengembangan pendidikan Islam berbasis madrasah diniyah dalam era revolusi industri 4.0 yang mengakibatkan perubahan zaman dan IPTEK. Perlunya pengembangan seperti kurikulum yang sesuai dan terus berkembang atau terupdate yang dapat menunjang pembelajaran, penambahan pembekalan guru agar lebih berkompeten, penambahan

${ }^{4}$ Zulfa Hanun Alfi Syahr, "Membentuk Madrasah Diniyah Sebagai Alternatif Lembaga Pendidikan Elite Muslim Bagi Masyarakat”, Intizar, Vol. 22 No. 2, (2016), 406408. 
fasilitas sebagai sarana penunjang pengembangan pendidikan Islam yang berbasis madrasah diniyah, manajemen dan administrasi yang tertata serta sosialisai terhadap masyarakat agar pendidikan Islam bebrasis madrasah diniyah ini dapat diterima semua kalangan, bahkan dapat menjadi pendidikan yang bersifat wajib bila sangat diperlukan dalam masyarakat, sehingga ada kontribusi masyarakat, yayasan, dan juga pemerintah dalam pengembangan pendidikan Islam yang bebasis madrasah diniyah. ${ }^{5}$

Dalam hal ini dengan adanya pemerhatian sarana pendidikan atau lembaga pendidikan dari semua pihak, madrasah diniyah akan berkembang dan dapat bersaing dalam era revolusi industri yang mana zaman ini adalah zaman modern, tetapi madrasah diniyah harus berani maju untuk berkembang agar menjadi garda terdepan pendidikan yang berbasis keIslaman sebagai sarana pembentukan insan berakal dan berakhlakul karimah dan dapat terjun dalam masyarakat yang sangat pesat terpengaruh oleh globalisasi sehingga banyak sekali tantangan dan problematika yang akan terjadi dihari ini dan hari yang akan datang.

Dalam perkembanganya, madrasah diniyah tidak hanya mengajarkan tentang keislaman saja namun juga dapat mengajarkan tentang nilainilai yang seharusnya ada dan dipergunakan dalam masyarakat seperti tolong menolong, rela berkorban, toleransi, pluralisme, perilaku terpuji dan penambahan aspek keimanan setiap idividu, sehingga bukan hanya menjadi seorang yang agamis namun juga menjadi seorang yang nasionalis, karena cinta tanah air yang mereka tumbuhkan menjadi bekal mereka kuat menghadapi perubahan zaman ${ }^{6}$

Seseorang akan bermanfaat apabila dia mengerti dan juga dapat beradaptasi dalam berbagai hal dan tempat, sehingga mereka mampu menjawab problematika masyarakat yang semakin hilang identitas. Dengan adanya pengembangan pendidikan Islam dan pendidikan budi pekerti dan kemoralan dalam madrasah diniyah dapat diharapkan bahwa

5 Anis Fauzi dan Cecep Nikmatullah, "Pelaksanaan Pendidikan Madrasah Diniyah Di Kota Serang", Jurnal Pendidikan dan Kebudayaan, Vol. 1 No. 2, (Agustus 2016), 160.

6 Aldila Ana Prastika, "Internalisasi Nilai Nasionalisme Melalui Madrasah Diniyah Takmiliyah Terintegrasi “Al-Latif” Di SD Negeri Suryodiningratan 2 Yogyakarta”, Jurnal Kebijakan Pendidikan, Vol. 6 No. 1, (2017), 18. 
kelak peserta didik dapat menjadi insan yang tangguh jasmani dan rohaninya dalam perubahan zaman ini, sedini mungkin harus ditanamkan nilai-nilai yang diperlukan untuk membentengi dari perubahan zaman, sehingga dapat memunculkan eksistensi yang lebih sentral dari madrasah diniyah ini.

\section{Dampak Yang Ditimbulkan Era Revolusi Industri 4.0 Terhadap Madrasah Diniyah}

Era globalisasi dalam revolusi industri 4.0 yang sangat gencar dengan majunya teknologi tentunya berdampak sangat fatal apabila madrasah diniyah tidak mampu mengikuti perubahan zaman, dampak yang disebabkan antara lain lunturnya tradisi yang telah berakulturasi dengan Islam yang dibawa oleh para wali pada zaman dahulu, moral dan adab peserta didik yang kurang terpelihara, eksistensi madrasah diniyah yang mulai tergerus waktu, cara mengajar tradisional yang terancam tidak dapat bersaing dalam kancah pendidikan, madrasah diniyah tidak dapat menjawab problematika masyarakat serta adanya kesenjangan antara pendidikan formal dan non formal, kesenjangan sosial, kesenjangan kualitas pendidikan yang dilaksanakan. ${ }^{7}$

Dampak-dampak tersebut akan mengakibatkan terjadinya kemunduran dari pendidikan yang berbasis madrasah diniyah sehingga terpandang lebih rendah dalam pelaksanaannya, madrasah diniyah harusnya dapat menyesuaikan posisinya dalam era modern, karena dengan begitu akan terus hidup sebuah madrasah diniyah dan mengadakan evaluasi untuk menghadapi dampak-dampak seperti yang kami jelaskan di atas.

\section{Penutup}

Pada kesimpulan ini, madrasah diniyah adalah salah satu tonggak pendidikan berbasis keislaman yang dapat direkomendasikan menjadi lembaga pendidikan yang berbasis Islam dan mengajarkan tentang agama dan nasionalisme bernegara yang bertujuan pengamalan ilmu

\footnotetext{
7 Marwan Salahuddin, "Reposisi Dan Eksistensi Madrasah Salafiyah Di Era Global", Cendekia, Vol. 11 No. 2, (Desember 2013), 222.
} 
di kehidupan. Dan tujuannya adalah mencetak dan mengkader peserta didiknya menjadi insan yang berakal, beriman dan berakhlakul karimah serta mempunyai keterampilan dibidangnya.

Peran sentral madrasah diniyah adalah sebagai wadah penunjang pembelajaran keagamaan Islam yang dapat berperan menghadapi era modern, namun sangat disayangkan peran ini sedikit terhambat karena beberapa keterbatasan dan kekurangan perhatian dari pihak terkait dan juga masyarakat.

Pengembangan pendidikan Islam berbasis madrasah diniyah perlu dikembangkan lagi selain dalam belajar dan mengaji juga perlu ditanamkan jiwa nasionalis dan juga penerapan norma-norma dan juga penambahan pendidikan yang bersifat ketrampilan agar peserta didik dapat bersaing dalam ranah kehidupan.

Dampak-dampak yang sangat disayangkan dari kemunculan era revolusi industri 4.0 sehingga menimbulkan banyak problematika yang terjadi, seharusnya madrasah diniyah dapat lebih terbuka dalam perubahan zaman namun dengan batasan-batasan tertentu agar tidak terjerumus dalam modernisasi yang sangat berbahaya dan menjadi benteng pembekalan sejak dini terhadap peserta didik dalam kehidupan bermasyarakat yang serba modern.

\section{Daitar Pustaka}

Ana Prastika, Aldila. "Internalisasi Nilai Nasionalisme Melalui Madrasah Diniyah Takmiliyah Terintegrasi "Al-Latif" Di SD Negeri Suryodiningratan 2 Yogyakarta". Jurnal Kebijakan Pendidikan. Vol. 6 No. 1. (2017).

Fauzi, Anis dan Nikmatullah, Cecep. "Pelaksanaan Pendidikan Madrasah Diniyah Di Kota Serang". Jurnal Pendidikan dan Kebudayaan. Vol. 1 No. 2. (Agustus 2016).

Hanun Alfi Syahr, Zulfa. "Membentuk Madrasah Diniyah Sebagai Alternatif Lembaga Pendidikan Elite Muslim Bagi Masyarakat". Intizar. Vol. 22 No. 2. (2016). 
Jamhuri, M. “Upaya Pendidikan Madrasah Diniyah Dalam Meningkatkan Prestasi Belajar Siswa Pada Materi Fiqih Di Madrasah Diniyah MIftahul Ulum Pruten Ngembal Pasuruan". Al-Murabbi: Jurnal Pendidikan Islam. Vol. 2 No. 2. (Juni 2017).

Salahuddin, Marwan. "Reposisi Dan Eksistensi Madrasah Salafiyah Di Era Global". Cendekia. Vol. 11 No. 2. (Desember 2013)

Toriqul Chaer, Mohammad. "Peran Madrasah Dalam Menghadapi Era Globalisasi Dan Budaya”. Muaddib. Vol. 6 No. 2. (Juli-Desember 2016). 